\title{
Study on the System of Chinese Occupational Tobacco Farmer Classification Evaluation and Application
}

\author{
Liu Jun ${ }^{1,}$ a, Wang Feng ${ }^{2, b}$ \\ ${ }^{1}$ Guizhou University of Finance and Economics, Guiyang 550025 \\ ${ }^{2}$ Branch of Tobacco Company in Southwest Guizhou Province, Xingyi 562400

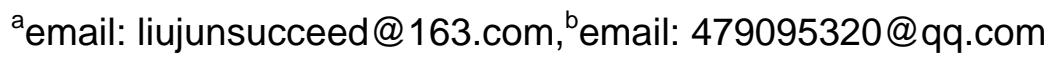

Keywords: Occupational Tobacco Growers; Factor Analysis Method; Evaluation System

\begin{abstract}
The continued decline in tobacco farmer and high-age structure have been highly valued by the leadership of tobacco departments and production areas. Under the background that modern tobacco agriculture is deepened promoted and occupational services capability of farmers cooperatives is continuously upgrade, this paper analyzes the definition and characteristics of occupational farmers, identifies 13 objective indicators from five dimensions "tobacco-oriented" "integrity" "culture", "technology " "management", with factor analysis method of objective determining weights, build a set of scientific and reliable evaluation index system and give application research.
\end{abstract}

\section{Introduction}

As a kind of typical labor-intensive agricultural production, tobacco production is large investment, high-risk, labor-intensive, high strength, long period, long industrial chain and technology-intensive. In spite of the construction of modern tobacco agriculture since 2007, tobacco production has achieved cost reduction and less work. But in terms of migrant workers and other economic crops, the reality of large labor intensity and low yield has not changed. A large number of farmers no longer grow tobacco, even out of village, no longer engaged in agricultural production. The number of tobacco farmers continues to decline. According to the statistics, the number of tobacco growers in GuiZhou from the 725, 000 at the end of year 2,000 rapidly reduced to 135,000 at the beginning of year 2015, with an average annual decrease of 10.6 percent. More serious is that proportion of tobacco farmers who are under 30 year old decreased from 7 percent in year 2008 to 3.2 percent in year 2014, proportion of tobacco farmers between 30 years old to 40 years decreased from 43 percent to 19.6 percent, proportion of tobacco farmers who are over 50 years increased from 13 percent to 33.1 percent. A large number of young and middle-aged farmers no longer grow tobacco.

In 2013, the State Tobacco Bureau put forward that the key of tobacco industry's sustainable development is to solve the problem of " who is responsible for planting tobacco," cultivate occupational tobacco growers, occupational services team and industry workers, accelerate three separate: land ownership, operation management and occupational services ${ }^{[1]}$. In order to solve the decrease of tobacco farmers, producing areas have begun to train occupational tobacco growers. But the understanding to occupational tobacco growers is very different. Some areas put the occupational tobacco growers understand "agricultural workers" in growing cooperatives. Some areas consider that people with high-level ability to grow tobacco is occupational tobacco growers. Some areas think that as long as farmers whose planting scale beyond a certain degree are occupational tobacco growers. These one-sided misunderstandings may mislead the cultivation of occupational tobacco growers, even make it become a formality. So what kind of farmers are occupational tobacco growers, how many types are there, how to assess them, what is evaluation standard, what is the difference between the current farmers and them? With the actual situation of mountain, the author conducts applied research, hoping to provide reference for the cultivation of occupational tobacco growers. 


\section{Connotation of Occupational Farmers}

To understand the concept of occupational tobacco farmers, we must understand the concept of occupation farmers, which did not have a clear and unified definition. There are some similar concepts, such as "occupational farmers", "farmers professionalism", "farmers specialization ", etc. Wolf Eric said that occupational farmers treat agriculture as an industry, fully free to enter market, use all the possible conditions to maximize economic returns ${ }^{[2]}$. In China, Zhao Qiangshe ${ }^{[3]}$, Liu Jianlan $^{[4]}$, Li Hui ${ }^{[5]}$, Li Wenxue ${ }^{[6]}$, Zhu Qizhen ${ }^{[7]}$ and others defined the occupational farmers from their own research. The author believes that the definition of occupational farmers gave by Zhu Qizhen is more accurate. He thought occupational farmers are farmers who long-term live in rural communities and have long been engaged in agricultural production. Their economic sources mainly come from agricultural production and operating income. Based on this, he thought that occupational farmers must possess three conditions and characteristics. First, fully into the market, use every possible choice to maximize economic returns, generally have high income, as the market main body; second, with a high degree of stability, treat farming as a lifelong career, have successors, are different from short-term behavior of capital agriculture; third, have highly social responsibility and modern concept, new occupational farmers not only have culture, understand technology, well management, also require their behaviors are responsible for ecology, environment, society and future generations.

At the same time, the Ministry of agriculture, according to definition of occupational farmers and management status and development trend of agriculture production, divided new occupational farmers into three types ${ }^{[8]}$, namely, production management farmers, professional skilled farmers and social service farmers. Occupational farmers of production management point to someone who takes agricultures as a job, have certain resources, occupational skills, the ability to capital investment, whose income mainly come from agricultural labor, including professional investors, family farmers, farmers cooperatives leader, etc. Professional skilled farmers refer to the agricultural labor in farmers' cooperatives, family farms, professional investors, agricultural enterprises and other new production and management body, including agricultural workers, agricultural employees and others, who have certain expertise, engaged in agricultural produce. Occupational farmers of social service refer to social service organizations or individuals are directly engaged in produce antenatal, produce medium, postpartum agriculture service which are their main income source. They are agricultural social service person who have corresponding service ability, including messenger, brokers, agricultural machinery driver, agricultural service staff, plant protector, animal epidemic prevention staff and other agricultural social service person.

Therefore, the author believes that occupational farmers of production management farmers refer to someone who is a local rural, long-term lives in the countryside and has long been engaged in tobacco production by land, technology, facilities and equipment, etc. On this basis, Occupational farmers of production management should also have three conditions. First, continuously plant tobacco for many years, with a high degree of stability, family economic sources mainly come from tobacco production income; second, they have a certain management ability, accept occupational services provided by occupational cooperatives, through the complementary of production factors and specialization, according to the technical requirements of tobacco companies, carry out production. Their labor productivity, production level and benefits are higher than ordinary tobacco farmers; third, they have a high degree of contractual compliance rate, social responsibility and modern ideas, comply with all the rules and regulations of tobacco companies, complete the number and structure of purchase contract and bear the ecological and environmental responsibility to basic tobacco field. 


\section{Evaluation Index System of Occupational Tobacco Farmers}

\section{Index Design Idea.}

In this paper, the overall design of the index system is: with the guidance of AHP thought[8], by definition, five dimensions, connotation analysis and specific performance of each dimension, establish measurement index system, including target level, standard layer, index layer. First, target layer is established according to the definition. Evaluation target is occupational tobacco farmers of production and management, so target layer of index system shall be designed by surrounding professional level of tobacco farmers. Second, standard layer is established according to five dimensions. Finally, according to the connotation of each dimension and the specific performance, set up the index layer. The form of each dimension is diversified, so we need to avoid the qualitative indexes, process indexes and subjective indicators, select a specific indicators of quantitative and objective. This paper determines indicators index layer through the questionnaire survey.

\section{Index Selection.}

(1) Questionnaire design. First of all, the paper uses meta analysis method to extract the indicators of "culture" "technology" "management" about new farmers and occupational farmers, convert it to the indicators used in mountain areas and tobacco industry, as a part of an alternative. According to work experience of author, some new indicators of "tobacco-oriented" and "integrity" are put forward. Then the two part of alternative indicators are classified into five dimensions. We design questionnaire answers (very effective, effective, moderately effective, generally effective, invalid) for effectiveness of mountain farmers occupation about each alternative assessment, finally get questionnaire of "evaluation index of occupational farmers".

(2) Questionnaire investigation. According to alternative indexes, we designed questionnaires of "evaluation index of occupational farmers", carried out the questionnaires using Delphi method. A total of 29 experts who are engaged in tobacco production and cultivation of occupational farmers for a long time participated in investigation. After three rounds of advice, there are more than 80 percent of experts reach a consensus. A total of 13 indicators were identified, as shown in Table 1 . We increased veto of assessing dynamic management. Evaluation results will accept long-term supervision by farmers and society. The occupational farmers who fraudulently purchase and resell tobacco materials, profiteer tobacco, not according to technical requirements for production, will be disqualified.

Table 1 Evaluation Index System of Occupational Tobacco Farmers

\begin{tabular}{|c|c|}
\hline Income Share & Flue-cured Tobacco Income Accounted X1) \\
\hline Loyalty & Years of Planting Tobacco (x2) \\
\hline Potential & Age Structure (x3) \\
\hline \multirow{2}{*}{$\begin{array}{l}\text { Contract } \\
\text { Compliance }\end{array}$} & Quantity (X4) \\
\hline & Structure (X5) \\
\hline Education level & Education $(\mathrm{x} 6)$ \\
\hline Ideas & Accept Occupational Service (X7) \\
\hline \multirow{3}{*}{ Production Level } & Yields Per Acre (x8) \\
\hline & Output Value Per Acre (x9) \\
\hline & Proportion of High Quality Tobacco (x10) \\
\hline Special Skills & Large-scale Agricultural Operations, x11) \\
\hline Moderate Scale & Planting areas (X12) \\
\hline Management ability & Production Costs Per Acre (X13) \\
\hline
\end{tabular}

\section{Empirical Research}

According to table 1,from counties of planting tobacco, with 32production and purchase plan which are more than 100,000 dan in 9 States of Guizhou Province, we randomly selected each 10 planting areas of seven different scale: below $10 \mathrm{mu}, 10 \mathrm{mu}$ to $20 \mathrm{mu}, 20 \mathrm{mu}$ to 30 acres, 30 acres of 
50 acres, 50 acres to 100 acres, 100 acres to 500 acres and more than 500 acres. Questionnaire survey was conducted on 2136 tobacco farmers, and got 27768 groups data.

Delphi method is mostly used for evaluation index of occupational tobacco farmers to determine weight of each index. This article involves large amount of data. The limit of expert quantities of Delphi method requires (usually less than 50)make it hard to objectively reflect the weight of each index. So we will use factor analysis method of objective determination to determine the weight of each index.

\section{Weight Analysis.}

The total explain variance of 13 indexes was calculated by SPSS11.0 software, which is shown in Table 2.

Table 2 Total Variance Explained

\begin{tabular}{|c|c|c|c|}
\hline \multirow{2}{*}{ Ingredients } & \multicolumn{3}{|c|}{ Initial Eigenvalue } \\
\cline { 2 - 4 } & Total & $\begin{array}{c}\text { Variance } \\
\text { Percent }\end{array}$ & $\begin{array}{c}\text { Cumulative } \\
\text { Percent }\end{array}$ \\
\hline 1 & 2.321 & 17.362 & 17.231 \\
\hline 2 & 1.468 & 11.653 & 29.352 \\
\hline 3 & 1.165 & 9.665 & 39.126 \\
\hline 4 & 1.125 & 7.742 & 47.756 \\
\hline 5 & 0.991 & 7.913 & 55.962 \\
\hline 6 & .876 & 6.612 & 62.487 \\
\hline 7 & .842 & 6.906 & 70.698 \\
\hline 8 & .735 & 6.552 & 77.231 \\
\hline 9 & .659 & 5.586 & 82.153 \\
\hline 10 & .546 & 5.065 & 89.599 \\
\hline 11 & .524 & 4.721 & 93.513 \\
\hline 12 & .291 & 2.023 & 95.590 \\
\hline 13 & .234 & 2.452 & 100.000 \\
\hline
\end{tabular}

According to the above, we can obtain factor score function of occupational tobacco farmers evaluation as follows.

$$
\begin{gathered}
F_{1}=-0.038 \mathrm{X}_{1}-0.022 \mathrm{X}_{2}-0.132 \mathrm{X}_{3}+0.213 \mathrm{X}_{4}+0.041 \mathrm{X}_{5}+0.2198 \mathrm{x}_{6}+0.135 \mathrm{x}_{7}+0.160 \mathrm{X}_{8} \\
+0.343 \mathrm{X}_{9}-0.015 \mathrm{X}_{10}-0.075 \mathrm{X}_{11}+0.278 \mathrm{X}_{12}-0.019 \mathrm{X}_{13} \\
F_{2}=0.110 \mathrm{X}_{1}-0.220 \mathrm{X}_{2}+0.241 \mathrm{X}_{3}+0.326 \mathrm{X}_{4}+0.020 \mathrm{X}_{5}-0.246 \mathrm{x}_{6}-0.319 \mathrm{x}_{7}-0.301 \mathrm{X}_{8} \\
-0.07 \mathrm{X}_{9}+0.110 \mathrm{X}_{10}-0.251 \mathrm{X}_{11}+0.268 \mathrm{X}_{12}+0.071 \mathrm{X}_{13} \\
F_{3}=0.459 \mathrm{X}_{1}-0.359 \mathrm{X}_{2}-0.306 \mathrm{X}_{3}-0.002 \mathrm{X}_{4}+0.001 \mathrm{X}_{5}-0.047 \mathrm{X}_{6}-0.109 \mathrm{x}_{7}-0.280 \mathrm{X}_{8} \\
-0.030 \mathrm{X}_{9}+0.027 \mathrm{X}_{10}+0.428 \mathrm{X}_{11}+0.267 \mathrm{X}_{12}+0.032 \mathrm{X}_{13} \\
F_{4}=0.255 \mathrm{X}_{1}+0.025 \mathrm{X}_{2}-0.095 \mathrm{X}_{3}+0.084 \mathrm{X}_{4}-0.157 \mathrm{X}_{5}+0.464 \mathrm{X}_{6}+0.051 \mathrm{x}_{7}+0.141 \mathrm{X}_{8} \\
-0.042 \mathrm{X}_{9}+0.341 \mathrm{X}_{10}-0.227 \mathrm{X}_{11}-0.009 \mathrm{X}_{12}+0.604 \mathrm{X}_{13} \\
F_{5}=-0.049 \mathrm{X}_{1}+0.295 \mathrm{X}_{2}+0.232 \mathrm{X}_{3}-0.372 \mathrm{X}_{4}+0.233 \mathrm{X}_{5}-0.172 \mathrm{X}_{6}+0.064 \mathrm{X}_{7}+0.032 \mathrm{X}_{8} \\
+0.135 \mathrm{X}_{9}+0.624 \mathrm{X}_{10}+0.394 \mathrm{X}_{11}+0.085 \mathrm{X}_{12}+0.083 \mathrm{X}_{13}
\end{gathered}
$$

Comprehensive scoring function of tobacco farmers occupational level is got by binary regression analysis method .

$$
\mathrm{F}=0.112 \mathrm{~F}_{1}+0.190 \mathrm{~F}_{2}+0.172 \mathrm{~F}_{3}+0.311 \mathrm{~F}_{4}+0.231 \mathrm{~F}_{5}
$$

Occupational Level Analysis of Tobacco Farmers.

The $1378 * 6$ data were obtained by randomly selected from 6 counties of southwest Guizhou, substituted into equation 6 , overall score of occupational farmers can be got. 
Table 3 Overall Score of Occupational Farmers In 6 Counties Of Southwest Guizhou

\begin{tabular}{|c|c|c|}
\hline Unit & $\begin{array}{c}\text { Occupation } \\
\text { Level }\end{array}$ & Management \\
\hline Xingyi & 0.644 & 0.665 \\
\hline Anlong & 0.599 & 0.633 \\
\hline Puan & 0.684 & 0.699 \\
\hline Xingren & 0.778 & 0.845 \\
\hline Zhenfeng & 0.641 & 0.589 \\
\hline Qinglong & 0.644 & 0.558 \\
\hline
\end{tabular}

\section{Research Results and Analysis}

Analysis from occupational level and occupational level interval of tobacco farmers, our province farmer occupation level is not high at present. Proportion of occupational tobacco farmers who can directly carry out identification is only about 30 percent. It is imbalance between regions, especially in "integrity", "technology" "management". since the country have put forward to cultivate occupational tobacco farmer in 2013, all areas have carried out the cultivation of occupational tobacco farmer for more than two years. Why is there such a big gap between tobacco farmer and occupational tobacco farmers? A fact should be recognized that if someone, especially farmers, need a long process of education and nurture to improve their quality. Compared with plain area, mountain farmers are subject to the economic and social development, information technology, etc.. Their quality is relatively low. It is more difficult to realize professionalism for them. Therefore, cultivation of occupational tobacco farmers cannot be done overnight which is a slow effect, long cycle project. In addition to this reason, with case data collected by questionnaires, interviews and observation, we can get following several reasons.

(1) Assessment system is not perfect. Assessment system is the foundation of occupational tobacco farmers cultivation. But so far, the tobacco industry has not yet a unified and rational evaluation system. Each region gives evaluation with main indicators: implementation of production technology, average size. Dividing basis is unreasonable.

(2) Cultivation system is not perfect. Survey found that areas did not promote farmers widely the confidence and determination of current tobacco industry and governments to cultivate occupational tobacco farmers. Tobacco farmers didn't understand preferential support policy and differentiated service policy issued by tobacco departments, whose initiative is not strong. For the training of occupational tobacco farmer, each region has not serious to the arrangement of time, content, place and manner, which leads to conflict between training task and the life of tobacco farmers. Training content involves more production technology, less production management, policies and regulations.

(3) Security system is not perfect. Most of regions did not carry out differentiation support measures according to different levels of tobacco farmers. They did not fundamentally change average distribution method according to traditional production factors. Farmers cannot feel the real benefits brought by cultivation of occupational tobacco farmers. Policy and measures in land circulation, credit support and planting insurance policies for tobacco farmers provided by regions are insufficient. Mountain tobacco farmers have more problems in scale planting, capital investment and minimum income guarantee, are inability to expand the scale of planting and cannot firmly take confidence and determination to go the occupational tobacco farmers road. 


\section{Acknowledgment}

Research on evaluation of tobacco farmers classification and differential management in southwestern Guizhou (2011-15); Study on the mechanism of foreign assets of tobacco farmers cooperatives inclusive (2015-9); Guizhou Province Science and Technology Fund project ( Qiankehe J [2015] No. 2028); Science and technology project of China National Tobacco Corp Guizhou Branch (201224); National social science fund project (14CJL032).

\section{Reference}

[1] Wang Cheng. Sustainable Development of Tobacco Leaf Production [N]. Oriental Tobacco, 2014-1-14(1).

[2] Eric Wolf Peasants.[M].Englewood Cliffs, Prentice-Hall,1966:25.

[3] Zhao Qiangshe. Analysis on Path of Occupational Farmers Cultivation [J]. Theory Guide,2009(3):56-58.

[4] Liu Jianlan. Significance and Thought of Education and Training Platform Construction for Occupational Farmers[J]. Agricultural Science and Technology Management, 2010(5):37-38.

[5] Li Hui. Research on occupational farmers and cultivation mode [J]. Vocational and Technical Education in China, 2012(3):45-49.

[6] Li Wenxue. Four Characteristics of New Type of Occupational Farmers [J]. Rural Work Communication,2012(7):35.

[7] Zhu Qizhen. New Occupational Farmers and Family Farms [J]. Journal of China Agricultural University (Social Science Edition), 2013(6):157.

[8] Ministry of Agriculture. Guiding Opinions on Cultivation of New Type Occupational Farmers [Z].2013.

[9] Wu Dianting, Li Dongfang. Research on Shortage of AHP and Improving Way [J]. Journal of Beijing Normal University（Natural Science Edition）, 2004, 40 (2): 264-268.

[10]Kalyani Ankem. Approaches to Meta-Analysis: A Guide for LIS Researchers [J]. Library \& Information Science Research, 2005, 27(2):164-176. 